\title{
Tracking the Roots of Reading Ability: White Matter Volume and Integrity Correlate with Phonological Awareness in Prereading and Early-Reading Kindergarten Children
}

\author{
Zeynep M. Saygin, ${ }^{1 *}$ Elizabeth S. Norton, ${ }^{1 *}$ David E. Osher, ${ }^{1}$ Sara D. Beach, ${ }^{1}$ Abigail B. Cyr, ${ }^{1}$ Ola Ozernov-Palchik, ${ }^{3}$ \\ Anastasia Yendiki, ${ }^{4}$ Bruce Fischl, ${ }^{2,4}$ Nadine Gaab, ${ }^{3}$ and John D.E. Gabrieli ${ }^{1}$ \\ ${ }^{1} \mathrm{McGovern}$ Institute for Brain Research and Department of Brain and Cognitive Sciences and ${ }^{2}$ Computer Science and Artificial Intelligence Laboratory, \\ Massachusetts Institute of Technology, Cambridge, Massachusetts 02139, ${ }^{3}$ Division of Developmental Medicine, Laboratories of Cognitive Neuroscience, \\ Boston Children's Hospital, Boston, Massachusetts 02115, and ${ }^{4}$ Athinoula A. Martinos Center for Biomedical Imaging, Massachusetts General Hospital and \\ Harvard Medical School, Charlestown, Massachusetts 02129
}

Developmental dyslexia, an unexplained difficulty in learning to read, has been associated with alterations in white matter organization as measured by diffusion-weighted imaging. It is unknown, however, whether these differences in structural connectivity are related to the cause of dyslexia or if they are consequences of reading difficulty (e.g., less reading experience or compensatory brain organization). Here, in 40 kindergartners who had received little or no reading instruction, we examined the relation between behavioral predictors of dyslexia and white matter organization in left arcuate fasciculus, inferior longitudinal fasciculus, and the parietal portion of the superior longitudinal fasciculus using probabilistic tractography. Higher composite phonological awareness scores were significantly and positively correlated with the volume of the arcuate fasciculus, but not with other tracts. Two other behavioral predictors of dyslexia, rapid naming and letter knowledge, did not correlate with volumes or diffusion values in these tracts. The volume and fractional anisotropy of the left arcuate showed a particularly strong positive correlation with a phoneme blending test. Whole-brain regressions of behavioral scores with diffusion measures confirmed the unique relation between phonological awareness and the left arcuate. These findings indicate that the left arcuate fasciculus, which connects anterior and posterior language regions of the human brain and which has been previously associated with reading ability in older individuals, is already smaller and has less integrity in kindergartners who are at risk for dyslexia because of poor phonological awareness. These findings suggest a structural basis of behavioral risk for dyslexia that predates reading instruction.

\section{Introduction}

Developmental dyslexia, an unexplained difficulty in learning to read, affects $\sim 10 \%$ of children in the United States (Lyon et al., 2003). Dyslexia is associated with atypical brain function for reading, especially reduced activation in left temporoparietal regions (Gabrieli, 2009) that is independent of current reading abil-

\footnotetext{
Received Sept. 13, 2012; revised June 7, 2013; accepted June 12, 2013.

Author contributions:Z.M.S., E.S.N., N.G., and J.D.E.G. designed research;Z.M.S., E.S.N., S.D.B., A.B.C., and 0.0.-P. performed research;Z.M.S., E.S.N., D.E.O., S.D.B., A.Y., B.F., N.G., and J.D.E.G. analyzed data; Z.M.S., E.S.N., A.Y., B.F., N.G., and J.D.E.G. wrote the paper.

This work was supported by grants from the National Institutes of Health-National Institute of Child Health and Human Development (Grant \#R01 HD067312), the National Institutes of Health-National Institute of Biomedical Imaging and Bioengineering (Grant \#K99/R00 EB008129), the Halis Family Foundation, and the Ellison Medical Foundation. We thank Christina Triantafyllou, Steven Shannon, Sheeba Arnold, and the Athinoula A. Martinos Imaging Center at the McGovern Institute for Brain Research at MIT, Tyler Perrachione, Carlos Cardenas, Keri-Lee Garel, and Rebecca Winter for technical assistance, and our research testers, school coordinators and principals, and participating families. Participating schools are listed on our website: http://gablab.mit.edu/index.php/READstudy.

The authors declare no competing financial interests.

*Z.M.S. and E.S.N. contributed equally to this work.

Correspondence should be addressed to either Zeynep M. Saygin or Elizabeth S. Norton, Massachusetts Institute of Technology, 43 Vassar St., 46-4033, Cambridge, MA 02139; E-mail: zsaygin@mit.edu or esn@mit.edu.

DOI:10.1523/JNEUROSCI.4383-12.2013

Copyright $\odot 2013$ the authors $\quad 0270-6474 / 13 / 3313251-08 \$ 15.00 / 0$
}

ity (Hoeft et al., 2007) or IQ (Tanaka et al., 2011). Dyslexia is also associated with structural differences in white matter as measured by diffusion weighted imaging (DWI), specifically lower fractional anisotropy (FA) in the left hemisphere (for review, see Vandermosten et al., 2012a) and reduced white matter volume (Silani et al., 2005). These differences may reflect weakened white matter connectivity among left-hemisphere areas that support reading. This interpretation is bolstered by evidence that similar DWI measures correlate with reading skill (Klingberg et al., 2000; Beaulieu et al., 2005; Deutsch et al., 2005; Dougherty et al., 2007; Hoeft et al., 2011).

A fundamental question is whether white matter structural differences are a cause or a consequence of poor reading in dyslexia. Prior DWI studies have not answered this question because they examined children and adults with extensive reading experience, and children with reading difficulty tend to read far less than typically reading peers (Cunningham and Stanovich, 1998) and appear to develop alternative reading pathways (e.g., enhanced righthemisphere activation; Shaywitz et al., 2002). The most direct way to evaluate whether white matter differences contribute to the etiology of dyslexia is to examine kindergartners for whom reading instruction and experience is unlikely to influence brain structure. 
Table 1. Demographic information and scores for participants $(n=40)$

\begin{tabular}{lcc}
\hline Measure & Mean (SD) & Range \\
\hline Age (years;months) & $5 ; 6(0 ; 5)$ & $4 ; 10-6 ; 4$ \\
KBIT-2 matrices SS & $100.9(10.3)$ & $85-120$ \\
PPVT-4 vocabulary SS & $116.2(12.8)$ & $83-160$ \\
PA composite SS & $10.3(1.8)$ & $7.3-15.3$ \\
RAN composite SS & $97.5(13.5)$ & $68.3-122.3$ \\
LK composite SS & $106.8(10.2)$ & $87.0-132.0$ \\
Word ID raw score & $12.8(19.3)$ & $0-67$ \\
\hline
\end{tabular}

LK, Letter knowledge; SS, Standard Score, in which standardized mean is 100 except for PA (CTOPP), in which it is 10.

Prereaders and early readers cannot exhibit dyslexia per se, but their prereading skills that predict later reading abilities can be evaluated. In English, such predictors are phonological awareness (PA; awareness of the sound structure of spoken words, which must be mapped onto letters to read), rapid automatized naming (RAN), and letter knowledge (Schatschneider et al., 2004). In children ages 7-11, PA correlated negatively with FA in callosal fibers connecting the temporal lobes (Dougherty et al., 2007). In adults, PA correlated positively with volume of the left superior longitudinal fasciculus (SLF; Frye et al., 2011) and with higher FA of the left arcuate fasciculus (Vandermosten et al., $2012 \mathrm{~b}$ ). The left arcuate is part of the SLF and connects temporoparietal and inferior frontal regions that are core constituents of the language network.

We hypothesized that if white matter differences are related to the cause of dyslexia, then such differences ought to be related to prereading skills that predict future reading ability. We examined two aspects of the left SLF (the arcuate fasciculus and SLFp, the frontoparietal aspect of the SLF) because of their importance in language and phonological awareness (Rauschecker et al., 2009; Yeatman et al., 2011; Vandermosten et al., 2012b), and the left inferior longitudinal fasciculus (ILF) because of its involvement in visual word-form processing (Cohen et al., 2003; Yeatman et al., 2012). We investigated whether these tracts were related to PA, RAN, and letter knowledge skills in prereading and early reading kindergartners. Finally, a whole-brain analysis examined the anatomic specificity of the tract-based findings.

\section{Materials and Methods}

\section{Overview}

As part of a larger study, children completed a short battery of psychoeducational assessments in their schools in New England in the spring of prekindergarten or fall of kindergarten before formal word reading instruction. Children with varying prereading skills were invited to take part in brain imaging. This study was approved by the institutional review boards at the Massachusetts Institute of Technology and Boston Children's Hospital. Parents gave written consent and children gave verbal assent to participate.

\section{Participants}

DWI data were collected from 52 children. Of these, 12 children had excessive motion (determined by visual inspection) and were excluded from subsequent analysis. Analyses included 40 children (21 females/19 males, 28 white/ 12 nonwhite; demographic information and scores are provided in Table 1). All children met eligibility criteria including: native speaker of American English; born after at least 36 weeks gestation; no sensory or perceptual difficulties other than corrected vision; no history of head or brain injury or trauma; no neurological, neuropsychological, or developmental diagnoses; no medications affecting the nervous system; and standard scores $>80$ on measures of nonverbal and verbal IQ (Kaufman Brief Intelligence Test [KBIT-2], Kaufman and Kaufman, 2004 Matrices; Peabody Picture Vocabulary Test [PPVT-4], Dunn and Dunn, 2007).

\section{Behavioral measures}

Phonological awareness. Three subtests from the Comprehensive Test of Phonological Processing (CTOPP; Wagner et al., 1999) were given to assess phonological skills: (1) Elision: the child repeats a word after removing a given sound (e.g., "say boat without saying /b/" = "oat"); (2) Blending Words: the child listens to a recorded series of sounds and blends them together to derive a real word (e.g., /m/-/a/-/t/ = "mat"); (3) Nonword Repetition: the child listens to a recorded made-up word (e.g., "sart") and repeats it. A composite standard score was created from the mean standard score for the three subtests (mean for each subtest is 10 , $\mathrm{SD}$ is 3 ). The range of standard scores for the CTOPP is limited for this age range because age 5 is the youngest age the test is normed for; a child who scores 0 on the Elision or Blending Words subtests receives a standard score of 7 , which is considered to be in the average range.

Letter knowledge. The letter identification subtest from the Woodcock Reading Mastery Test, Revised/Normative Update (WRMT-R/NU; Woodcock, 1998) was given to assess letter name knowledge. The Letter Sound Knowledge subtest from the York Assessment of Reading for Comprehension (YARC; Snowling et al., 2010) was given to assess knowledge of letter sounds and phoneme isolation skills. A composite was created from the mean standard scores for the YARC and WRMT-R subtests.

RAN. The Rapid Automatized Naming/Rapid Alternating Stimulus (RAN/RAS) tests (Wolf and Denckla, 2005) were given to measure the speed and efficiency of processes by which a series of randomly arranged stimuli are named. Subtests given were Object, Color, and Letter Naming. A composite was created from the mean standard scores for each subtest. For children who could not identify the letters during practice and thus did not receive a score for RAN Letters, a composite was created from the Objects and Colors subtests.

Word ID. The WRMT-R/NU (Woodcock, 1998) Word ID subtest was given to assess single word reading skills. In this test, the child is asked to read aloud single words of increasing difficulty. Raw scores were used to determine prereader versus reader status. Prereaders were defined as children who correctly read 0 words or 1 word on this test.

\section{Image acquisition and processing}

Data were acquired on a 3 T Siemens Trio Tim MRI scanner with a standard Siemens 32-channel phased array head coil. A whole-head, high-resolution T1-weighted multiecho MPRAGE (van der Kouwe et al., 2008) anatomical volume was acquired (acquisition parameters: TR = $2350 \mathrm{~ms}, \mathrm{TE}=1.64 \mathrm{~ms}, \mathrm{TI}=1400 \mathrm{~ms}$, flip angle $=7^{\circ}, \mathrm{FOV}=192 \times 192$, 176 slices, voxel resolution $=1.0 \mathrm{~mm}^{3}$, acceleration $=4$ ). An online prospective motion correction algorithm was implemented to reduce the effect of motion artifacts during the structural scan, and 10 selective reacquistion time points were acquired and included to replace time points that were affected by head motion (Tisdall et al., 2012). The diffusion-weighted scan (5 min total) included 10 non-diffusionweighted volumes $(b=0)$ and 30 diffusion-weighted volumes acquired with non-colinear gradient directions $\left(b=700 \mathrm{~s} / \mathrm{mm}^{2}\right)$, all at $128 \times 128$ base resolution and isotropic voxel resolution of $2.0 \mathrm{~mm}^{3}$.

Structural MRI data were processed using a semiautomated processing stream using the default parameters in FreeSurfer v5.1.0 (Dale et al., 1999; Fischl et al., 2002, 2004; Desikan et al., 2006; http://surfer.nmr. mgh.harvard.edu/), which includes motion and intensity correction, surface coregistration, spatial smoothing, subcortical segmentation, and cortical parcellation based on spherical template registration. Diffusionweighted images were checked for motion artifact and processed using FreeSurfer's TRACULA and FSL's FDT software (http://www.fmrib.ox. ac.uk/fsl/fdt/index.html).

\section{Tract-of-interest analyses}

We defined the tracts of interest using FreeSurfer's TRACULA (Yendiki et al., 2011), an automated method that reconstructs probabilistic distributions of major white matter tracts from each participant's native diffusion images. This method has been shown to accurately reconstruct tracts in individual subjects (compared with manual labeling) using anatomical priors. It uses a tract atlas of manually labeled tracts and FreeSurfer anatomical segmentations from a separate group of individuals to 
obtain the probability of each tract traversing or neighboring the anatomical segmentations along its trajectory. These anatomical priors are incorporated in a probabilistic framework to guide tractography in each novel subject, which allows for individual variation while reconstructing tracts that are anatomically consistent across individuals.

Preprocessing included registering diffusion-weighted images to the $b=0$ images to compensate for motion and eddy-current distortions. A registration transform was computed using FreeSurfer's bbregister (Greve and Fischl, 2009) for mapping each participant's $b=0$ image to the native structural scan. Images were checked for registration errors and no corrections were necessary. Cortical parcellations and subcortical segmentations from each individual's FreeSurfer reconstruction were mapped to his/her DWI using the above transform. FSL's DTIFIT estimated the tensor fits at each voxel, which produced FA images. FSL's bedpostX applied the ball-and-stick model of diffusion to each individual's DWI per voxel (Behrens et al., 2007). FSL's FLIRT computed a registration transform of each participant's structural scan to the Montreal Neurological Institute 152 (MNI152) template. This, combined with the first transformation (DWI-to-structural), was used to map the anatomical priors from the tract atlas to the individual's native diffusion images. The priors were then combined with each individual's local diffusion orientations obtained from the ball-and-stick model, as well as the individual's anatomical segmentations, to estimate probability distributions for each of the major pathways in each individual's native DWI space. After visual inspection, tract volumes were extracted and FA values averaged over the tract per individual. Tensor fits were only used to calculate the FA measures and not in the tractography algorithm itself; the latter uses the ball-and-stick fit, which, unlike the tensor fit, can model multiple (here, up to two) diffusion directions at each voxel. Although the anatomical priors in the tract atlas are computed in MNI space, the information encoded in these priors consists of the anatomical labels that each tract traverses and neighbors in $x, y$, and $z$ along its trajectory, and not the exact spatial location of the tract in MNI space. Therefore, this method is less sensitive to misalignment than voxel-based approaches that rely on exact spatial correspondence between subjects.

We examined a priori three white matter tracts that connect critical components of language and reading networks and that have most often been associated with variation in reading ability: the left ILF and two separate components of the left SLF, the arcuate fasciculus and SLFp. The left ILF is important for visual processing of words (Cohen et al., 2003; Yeatman et al., 2012) and damage to this tract can result in alexia (Epelbaum et al., 2008), presumably due to its role in connecting low-level visual regions to the visual word form area (a fusiform region involved in processing word/letter strings; Dehaene et al., 2002). The SLF connects frontal regions to both the parietal cortices (via the SLFp) and to temporal cortices (via the arcuate fasciculus). In particular, FA measures of the left arcuate have been shown to correlate with phonological awareness in older readers (Yeatman et al., 2011, 2012; Vandermosten et al., 2012b) and an area including the left arcuate is the only region found to be significantly related to reading ability in a meta-analysis of studies relating whole-brain DWI measures and reading ability (Vandermosten et al., 2012a). A case study suggests that damage to the left SLF (including both the arcuate and SLFp) causes a profound deficit in learning to read, whereas damage to the right SLF causes visuospatial deficits (Rauschecker et al., 2009). Due to the importance of these tracts in reading and dyslexia, we first focused on the left ILF, arcuate, and SLFp and then examined their right hemisphere counterparts as controls to determine the anatomical specificity of the results.

\section{Whole-brain analyses}

We used Tract-Based Spatial Statistics (TBSS, Smith et al., 2006), part of FSL (Smith et al., 2004) to perform voxelwise regressions of the FA data. The native-space FA images (described above) were aligned to the MNI152 template standard space using the nonlinear registration tool FNIRT (Andersson et al., 2007a, 2007b) and averaged to create a mean FA image. This image was then thinned to create a mean "FA skeleton," which represents the centers of the tracts that were common to all the subjects (the FA threshold was set to 0.2). Each subject's aligned FA data were projected onto this skeleton and voxelwise cross-subject statistics were performed on the white matter skeleton. A multilinear regression was designed to model the relationship between FA and each of the three behavioral measures (PA, RAN, letter knowledge) while accounting for all of the control measures: PPVT, KBIT, head circumference, gender, and variance in signal-to-noise ratio across diffusion gradients.

\section{Statistical methods}

The relations between diffusion measures and behavioral assessments were tested with leave-one-out cross-validation Pearson's correlations using in-house code in MATLAB (R2011b; MathWorks). This crossvalidation procedure was implemented to ensure that the results were not driven by outliers and to increase their applicability to new datasets. Results were considered significant only if they passed $p<0.05$ for all 40 cross-validation loops. Similar to other methods of significance correction (e.g., Bonferroni), the leave-one-out procedure decreases the likelihood of spurious correlations: it reduces the probability of a type I error by requiring the results to be replicated $n$ (i.e., 40) times. Reported statistical values are the overall correlation coefficients $r$ and $p$ for the group as a whole (all $n$ subjects). In addition to the measures of interest, we performed the same cross-validation procedure for each control measure to be sure that other factors were not driving relations between brain and behavioral measures (correlations for continuous measures: PPVT, KBIT, head circumference, signal-to-noise ratio variance; $t$ tests for gender).

To control for multiple comparisons, we performed permutation testing on the correlations by randomly shuffling the data for 1000 permutations and creating a distribution of "chance" correlations for every correlation that we ran. We created a final distribution from the maximum $r$ coefficients of these permutations, taking into account all of the correlations, and compared the actual (nonshuffled) correlation coefficients with these values to assign significance at $p<0.05$ (two-tailed).

Further, we performed the same tract-based analyses separately for the group of 18 children defined as prereaders. In this subset of children, we also performed three independent stepwise regressions to identify the tracts, or combination of tracts, that explain most of the variance in each of the three behavioral measures. In addition to the left ILF, arcuate, and SLFp, FA values for the right hemisphere homologs were included as predictors in the multilinear regression and terms were removed or added based on model fit (both removal and entry significances were defined as $p<0.05 / 3$, corrected for each behavioral metric).

For the whole-brain analyses, FSL's Randomize tool with thresholdfree cluster-enhancement (Smith and Nichols, 2009) was used to perform 5000 permutation tests with a significance threshold set at $p<0.05$, FWE corrected for multiple comparisons across voxels.

\section{Results}

\section{Behavioral results}

Mean scores and score ranges are reported in Table 1. We also characterized children as "at risk" for dyslexia based on scores in each of the three constructs of interest to provide context for the degree of variation in our sample. Although there are no definitive behavioral criteria for identifying which kindergarten children will go on to have dyslexia, longitudinal research indicates that classifying the lowest $30 \%$ of children as at-risk yields the optimal balance between sensitivity and specificity (Catts et al., 2001; Torgesen, 2004). Considering a cutoff of below the $30^{\text {th }}$ percentile for age-based standard scores, the number of children from the sample of 40 who would be considered at risk in each category is 9 for PA, 13 for RAN, and 5 for letter knowledge. There is some overlap of these categories: 22 children were not at risk in any of the 3 categories, 11 in only 1 category, 5 in 2 categories, and 2 in all 3 categories. There were no differences between boys and girls on any behavioral measure (age, KBIT, PPVT, or composites of PA, RAN, or letter knowledge composites; independent samples $t$ tests, two-tailed, all $p>0.08$ ). 


\section{Brain analyses}

We performed correlations of volume and FA for the ILF, arcuate, and SLFp with behavioral predictors of dyslexia (Fig. 1). The volume of the left arcuate was significantly and positively correlated with individual composite scores on phonological awareness $(r=0.38, p=0.014)$. The average FA values of the left arcuate were also positively correlated with phonological awareness scores overall $(r=0.37, p=$ 0.020 ), but did not pass significance for 2 of 40 cross-validation loops. Neither volume nor FA of the left ILF or SLFp correlated significantly with phonological awareness scores. There were no significant correlations between any of the three tracts' volumes or FA values with RAN or Letter Knowledge scores or with head size and other control measures. The exception was that PPVT scores correlated positively with SLFp volume $(r=0.37, p=0.017)$, which passed random permutation but not cross-validation testing. There were no differences between males and females in white matter measures.

We explored which specific components of the phonological awareness composite score (Elision, Blending Words, or Nonword Repetition raw scores) were driving the correlation seen with the left arcuate. The volume of the left arcuate showed significant positive correlations only with the Blending Words raw scores $(r=0.38, p=0.015$; Fig. $2 a)$. Blending Words raw scores also correlated positively with the tract's average FA $(r=0.43$, $p=5.70 \times 10^{-3}$; Fig. $2 b$ ). Scores for Blending Words correlated with the other phonological awareness measures (with Elision $r=0.69, p<0.001$, and with Nonword Repetition $r=0.45, p=$ $3.30 \times 10^{-3}$ ); the score range and SD were similar across the three measures. Three-dimensional renderings of the left arcuate tracts, which were ordered by volume and colored by FA values, illustrated these results (Fig. 2c). Elision and Nonword Repetition subtests alone were not significantly correlated with any of the tracts' diffusion measures.

Results were similar in analyses restricted to the 18 prereading children. Phonological awareness scores correlated significantly with volume $\left(r=0.74, p=3.98 \times 10^{-4}\right)$ and FA $(r=0.58, p=$ 0.011 ) of the left arcuate, but not with the left ILF. None of the other tracts' measures were significantly correlated with phonological awareness. In separating the phonological awareness composite score, only the Blending Words subtest of the CTOPP, not the other subtests, was significantly correlated with the volume $\left(r=0.74, p=4.19 \times 10^{-4}\right)$ and FA $(r=0.58, p=0.011)$ of the arcuate (Fig. $3 a, b)$.

We also performed a stepwise regression to examine the hemispheric specificity of our findings and to determine whether a combination of tracts would explain any of the three behavioral measures. Of the six tracts (bilateral ILF, arcuate, and SLFp), only the left arcuate fasciculus was found to be a significant predictor of phonological awareness $\left(t=2.88\right.$; $p=0.011$; model $R^{2}=$ 0.34 ). The other behavioral measures (RAN and letter knowledge) were not significantly predicted by the FA values of any tract.

Finally, whole-brain analyses were performed to assess the anatomical specificity of the tract-based analyses. Phonological awareness composite scores showed a positive relation with FA values in a cluster near the arcuate fasciculus (Fig. $4 ; p<0.05$ corrected; peak MNI coordinates $-42,-54,28)$. No other clus- ters showed correlations of FA with phonological awareness scores and no other behavioral measures were correlated with FA across the brain.

\section{Discussion}

In kindergarten children, we found a correlation between phonological awareness for spoken language and indices of white matter organization of the left arcuate fasciculus, specifically volume and FA. This relationship was both anatomically and behaviorally specific; it was not observed in other tracts (left ILF, left SLFp, or right hemisphere homologs) or for other behavioral predictors of dyslexia. These results were observed in the whole group of 40 children with varied reading abilities in the first half of kindergarten and also in the subset of 18 children who were prereaders. The specific relation between phonological awareness and the left arcuate fasciculus was corroborated by an independent whole-brain analysis. The discovery that such a relation between white matter organization and one of the strongest behavioral predictors of dyslexia, poor phonological awareness, exists before formal reading instruction and substantial reading experience favors the view that differences in white matter organization are not only the consequence of dyslexia, but also may be a cause of dyslexia.

The relation between a reading-relevant language skill and left arcuate white matter is consistent with studies in older children and adults finding that the most common relation between reading ability and white matter is observed in the left hemisphere temporoparietal region (Vandermosten et al., 2012a). Multiple studies have associated reading ability with white matter pathways, often with anterior-posterior fiber orientation, in the left temporoparietal region, such as the arcuate and other parts of the SLF (Klingberg et al., 2000; Nagy et al., 2004; Niogi and McCandliss, 2006; Richards et al., 2008; Carter et al., 2009; Rimrodt et al., 2010; Frye et al., 2011; Yeatman et al., 2011). Other studies have found relations between reading ability and white matter with inferior-superior fiber orientation such as the anterior and superior corona radiata (Beaulieu et al., 2005; Niogi and McCandliss, 2006; Qiu et al., 2008; Odegard et al., 2009), although we did not observe this in our whole-brain analysis. Causal evidence for the role of the left arcuate fasciculus in learning to read comes from the finding that learning to read enhanced FA in left arcuate fasciculus in ex-illiterate adults who learned to read during adulthood (Thiebaut de Schotten et al., 2012). Overall, these findings support the expected importance of a white matter tract that 


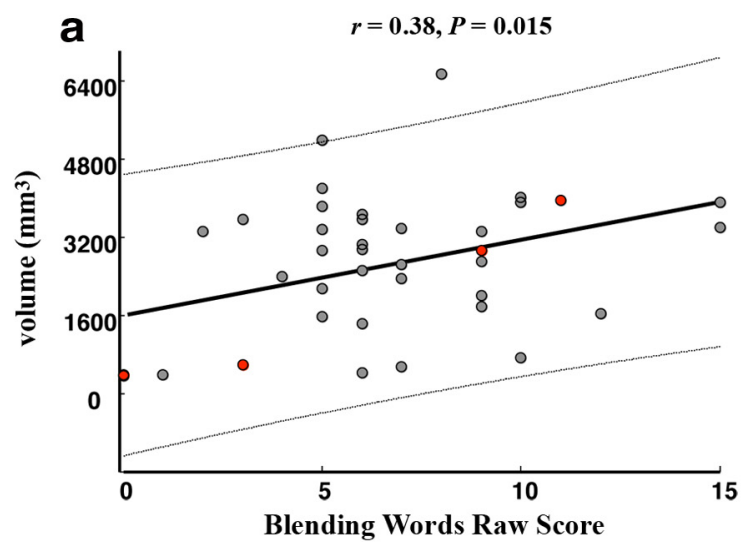

C

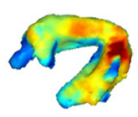

BW score $=0$

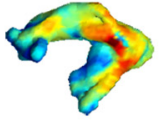

$\mathrm{BW}$ score $=3$

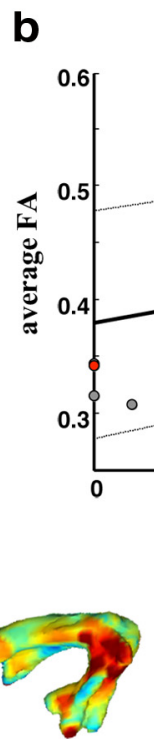

$\mathrm{BW}$ score $=9$ $r=0.43, P=5.7 \times 10^{-3}$

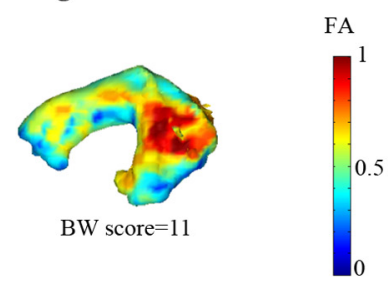

Figure 2. Greater volume and FA of the left arcuate fasciculus are associated with superior phonological awareness. $\boldsymbol{a}$, Volume of the left arcuate fasciculus plotted against individual raw scores of the Blending Words subtest. $\boldsymbol{b}$, Phonological awareness, illustrated by Blending Words raw scores, was significantly correlated with average $F A$ of the left arcuate fasciculus. In $\boldsymbol{a}$ and $\boldsymbol{b}$, thick lines represent the best fits and thin outer lines represent the $95 \%$ confidence intervals. $\boldsymbol{c}$, To illustrate the relation between the behavioral phonological awareness scores with left arcuate volume and FA, this tract was rendered from example participants (filled red circles in $\boldsymbol{a}$ and $\boldsymbol{b}$ ) and colored according to FA. The tracts are ordered by Blending Words raw score increasing from left to right.
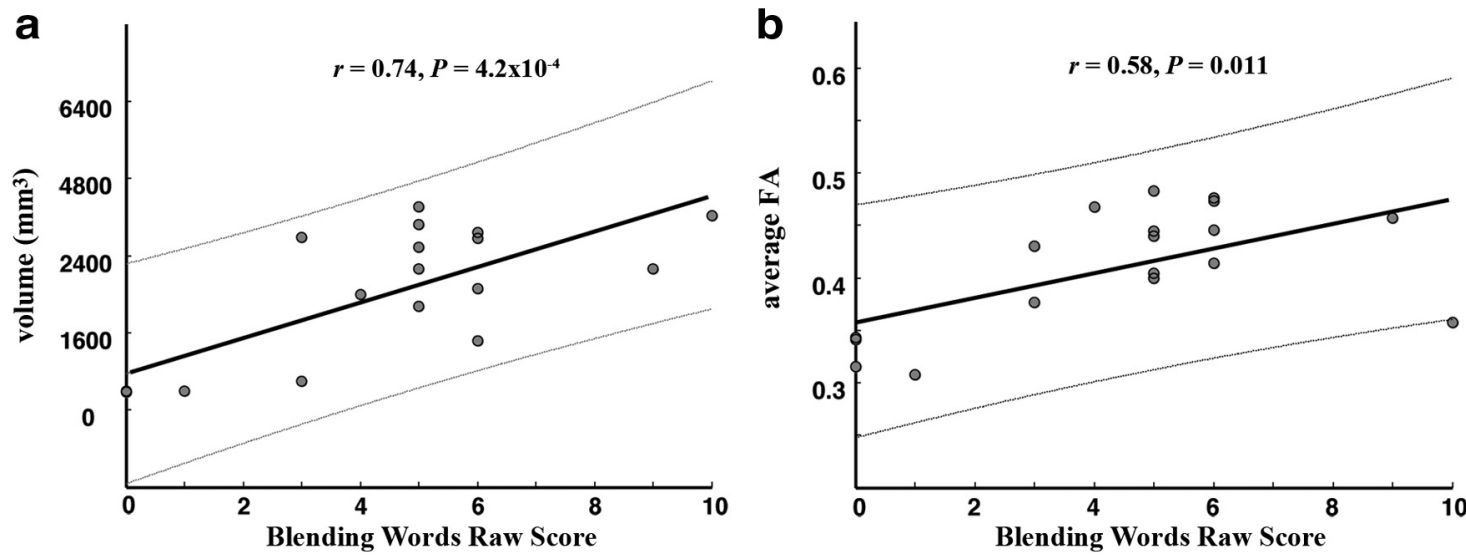

Figure 3. Greater volume and FA of the left arcuate fasciculus are associated with superior phonological awareness in prereading children. In prereading children (who could read 0 or 1 word), the Blending Words subtest scores were significantly correlated with the volume $(\boldsymbol{a})$ and the average FA $(\boldsymbol{b})$ of the left arcuate.

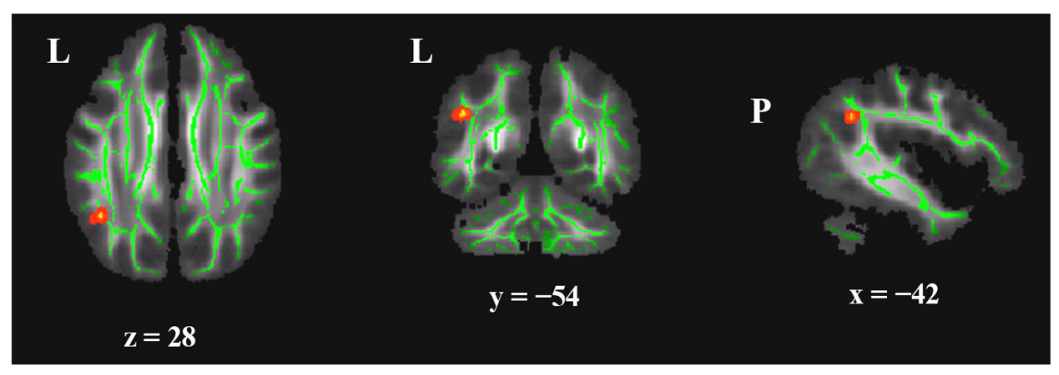

Figure 4. Whole-brain voxelwise analyses of the relation between FA and behavioral predictors of dyslexia. TBSS analyses revealed that FA values were associated only with phonological awareness scores and only in a cluster of voxels (red) at the bend of the SLF near Wernicke's area, where the arcuate elbows toward the temporal lobe $(p<0.05$ corrected; cluster size $=22)$. All statistics were run on the standard skeleton obtained using TBSS and displayed on thickened skeletons for ease of viewing. (L, left; P, posterior). connects critical anterior and posterior language areas that are, in turn, essential for mapping language onto print.

Consistent with the present findings, greater FA in left arcuate fasciculus has been associated with superior phonological awareness in adults (Rolheiser et al., 2011; Vandermosten et al., 2012b). In contrast, a study in children ages 7-11 found that greater FA in left arcuate fasciculus was associated with inferior phonological awareness (Yeatman et al., 2011). In a longitudinal study of children ages 7-15 examining the left arcuate fasciculus, superior readers initially had lower FA that increased across 3 years, 
whereas inferior readers initially had higher FA that decreased over 3 years (Yeatman et al., 2012). Only a longitudinal study spanning prereading and reading children can offer strong evidence on this topic, but the combined findings suggest a dynamic developmental pattern such that in early (prereading) and late (later childhood and adult) stages there is a positive relation between left arcuate microstructure and language or reading ability, but in a middle stage of intensive reading acquisition, this relation temporarily reverses.

Reduced indices of white matter organization could reflect several aspects of white matter tracts, such as the axonal properties of the arcuate. Alternatively, there may be more crossing fibers in children with lower phonological awareness, which may lead to lower measures of FA. Measures of anisotropy change with age (Lebel and Beaulieu, 2011), but this developmental difference was not observable in the arcuate for the narrow (1.5year) age range of our participants.

Variation in left arcuate fasciculus volume and microstructure among prereading and early-reading children was associated specifically with phonological awareness, and not with other reading-related skills such as naming fluency or letter knowledge. The absence of any correlation between behavioral measures and properties of the left ILF, a white matter tract that connects visual and temporal cortices, may reflect the minimal reading experience of children in the present study. Indeed, other studies of children and adults with extensive reading experience have reported relations between measures of the left ILF and reading ability (Steinbrink et al., 2008; Yeatman et al., 2012).

There are several limitations in the present study. First, we did not observe DWI correlations with RAN or letter knowledge, which is consistent with a prior study reporting correlations specific to phonological awareness and not to other reading-related measures (Yeatman et al., 2011). Studies with greater statistical power may observe brain-behavior correlations for other predictors of poor reading. Alternatively, other structural or functional brain measures may offer more sensitive measures for the other predictors. Second, the availability of sensitive measures of phonological awareness for kindergarten children is limited. We used the CTOPP, a widely used phonological awareness measure, but because the test is designed for such a wide age range, its sensitivity is limited for such young children. Future studies may be able to better characterize other subcomponents of phonological awareness using measures that elicit a wider variety of scores in kindergarten children. Third, the correlations we observed are a product of the behaviors we assessed. For example, the ILF connects regions that may be involved in visual, as opposed to linguistic, aspects of reading and reading-relevant variation may not have been evident in the absence of behavioral measures sensitive to visual analysis of print.

The present study documents a relation between phonological awareness and the left arcuate fasciculus. Phonological awareness is thought to be an essential precursor for learning to read because it allows for the mapping of previously learned sound units of oral language onto print (Wagner and Torgesen, 1987). Accordingly, variation in phonological awareness is one of the strongest predictors of later reading ability, and weakness in phonological awareness is common in dyslexia (Torgesen et al., 1999; Melby-Lervag et al., 2012). In the present study, one test of phonological awareness, the Blending Words subtest measuring phoneme blending, was most strongly related to the characteristics of the left arcuate fasciculus. Phoneme blending may be a particularly sensitive predictor at this age among the many phonological awareness subskills that vary in their predictive power over development (Paris, 2005).

More generally, the present findings support the view that brain differences can make learning to read difficult before the commencement of substantial reading instruction and experience. Dyslexia is strongly heritable (Pennington, 1990), and studies have found brain differences in individuals at familial risk for dyslexia. Newborns at familial risk exhibit differences in eventrelated potentials to language sounds within hours or days of birth (Guttorm et al., 2001), and longitudinal studies report correlations between such event-related potential differences during infancy and later language and reading abilities (Molfese, 2000; Guttorm et al., 2005). Prereading children at familial risk for dyslexia also exhibit reduced gray-matter volume in left posterior cortex (Raschle et al., 2011) and reduced functional activation for phonological processing (Raschle et al., 2012). Prereading children at behavioral risk based on poor letter knowledge also show reduced activation in bilateral posterior areas for processing letters relative to false fonts (Yamada et al., 2011).

The present study cannot identify specific genetic or experiential factors (home or school environments) that influence the prereading development of phonological awareness and the white matter pathways that support such awareness. For example, variation in language experience in home environments may influence phonological skill development (Burgess, 2002) that, in turn, influences white matter development before kindergarten. Evidence that experience alters white matter comes from a study reporting that reading interventions in older children who were poor readers was associated with white matter plasticity in a different brain region (Keller and Just, 2009). Therefore, the present study does not define what experiential or genetic factors influence the development of the left arcuate fasciculus before reading instruction in school, but it does indicate that such variation in brain-behavior relations precedes learning to read.

A clinical and educational goal of reading research is to improve the accuracy with which children at risk for dyslexia are identified so that they can receive early, preventive intervention rather than intervention that follows years of reading failure (Strickland, 2002). Although behavioral measures of phonological awareness, RAN, and letter knowledge in kindergartners predict reading ability years later (Catts et al., 2001; Schatschneider et al., 2004), the sensitivity and specificity of these behavioral measures is modest (Pennington and Lefly, 2001). There is some evidence that brain measures substantially enhance the accuracy of predicting reading ability across a school year (Hoeft et al., 2007; Rezaie et al., 2011) or across multiple years (Maurer et al., 2009; Hoeft et al., 2011). The present study indicates that DWI measures of white matter organization reveal a specific structural risk factor for reading difficulty that, in combination with behavioral and other brain measures, may improve the identification of prereaders at risk for dyslexia.

\section{References}

Andersson JLR, Jenkinson M, Smith S (2007a) Non-linear optimisation. FMRIB technical report TR07JA1. www.fmrib.ox.ac.uk/analysis/techrep. Accessed Sept. 3, 2012.

Andersson JLR, Jenkinson M, Smith S (2007b) Non-linear registration, aka spatial normalisation. FMRIB technical report TR07JA2. www.fmrib.ox. ac.uk/analysis/techrep. Accessed Sept. 3, 2012.

Beaulieu C, Plewes C, Paulson LA, Roy D, Snook L, Concha L, Phillips L (2005) Imaging brain connectivity in children with diverse reading ability. Neuroimage 25:1266-1271. CrossRef Medline

Behrens TE, Berg HJ, Jbabdi S, Rushworth MF, Woolrich MW (2007) Probabilistic diffusion tractography with multiple fibre orientations: What can we gain? Neuroimage 34:144-155. CrossRef Medline 
Burgess SR (2002) The influence of speech perception, oral language ability, the home literacy environment, and pre-reading knowledge on the growth of phonological sensitivity: a one-year longitudinal investigation. Reading and Writing 15:709-737. CrossRef

Carter JC, Lanham DC, Cutting LE, Clements-Stephens AM, Chen X, Hadzipasic M, Kim J, Denckla MB, Kaufmann WE (2009) A dual DTI approach to analyzing white matter in children with dyslexia. Psychiatry Res 172:215-219. CrossRef Medline

Catts HW, Fey ME, Zhang X, Tomblin JB (2001) Estimating risk for future reading difficulties in kindergarten children: a research-based model and its clinical implications. Language, Speech, and Hearing Services in Schools 32:38-50. CrossRef

Cohen L, Martinaud O, Lemer C, Lehéricy S, Samson Y, Obadia M, Slachevsky A, Dehaene S (2003) Visual word recognition in the left and right hemispheres: Anatomical and functional correlates of peripheral alexias. Cereb Cortex 13:1313-1333. CrossRef Medline

Cunningham AE, Stanovich KE (1998) What reading does for the mind. American Educator 22:1-8.

Dale AM, Fischl B, Sereno MI (1999) Cortical surface-based analysis: I. Segmentation and surface reconstruction. Neuroimage 9:179-194. CrossRef Medline

Dehaene S, Le Clec'H G, Poline JB, Le Bihan D, Cohen L (2002) The visual word form area: a prelexical representation of visual words in the fusiform gyrus. Neuroreport 13:321-325. CrossRef Medline

Desikan RS, Ségonne F, Fischl B, Quinn BT, Dickerson BC, Blacker D, Buckner RL, Dale AM, Maguire RP, Hyman BT, Albert MS, Killiany RJ (2006) An automated labeling system for subdividing the human cerebral cortex on MRI scans into gyral based regions of interest. Neuroimage 31:968980. CrossRef Medline

Deutsch GK, Dougherty RF, Bammer R, Siok WT, Gabrieli JD, Wandell B (2005) Children's reading performance is correlated with white matter structure measured by diffusion tensor imaging. Cortex 41:354-363. CrossRef Medline

Dougherty RF, Ben-Shachar M, Deutsch GK, Hernandez A, Fox GR, Wandell BA (2007) Temporal-callosal pathway diffusivity predicts phonological skills in children. Proc Natl Acad Sci U S A 104:8556-8661. CrossRef Medline

Dunn LM, Dunn DM (2007) Peabody Picture Vocabulary Test, Ed 4. San Antonio, TX: Pearson.

Epelbaum S, Pinel P, Gaillard R, Delmaire C, Perrin M, Dupont S, Dehaene S, Cohen L (2008) Pure alexia as a disconnection syndrome: New diffusion imaging evidence for an old concept. Cortex 44:962-974. CrossRef Medline

Fischl B, Salat DH, Busa E, Albert M, Dieterich M, Haselgrove C, van der Kouwe A, Killiany R, Kennedy D, Klaveness S, Montillo A, Makris N, Rosen B, Dale AM (2002) Whole brain segmentation: automated labeling of neuroanatomical structures in the human brain. Neuron 33:341355. CrossRef Medline

Fischl B, van der Kouwe A, Destrieux C, Halgren E, Ségonne F, Salat DH, Busa E, Seidman LJ, Goldstein J, Kennedy D, Caviness V, Makris N, Rosen B, Dale AM (2004) Automatically parcellating the human cerebral cortex. Cereb Cortex 14:11-22. CrossRef Medline

Frye RE, Liederman J, Hasan KM, Lincoln A, Malmberg B, McLean J 3rd, Papanicolaou A (2011) Diffusion tensor quantification of the relations between microstructural and macrostructural indices of white matter and reading. Hum Brain Mapp 32:1220-1235. CrossRef Medline

Gabrieli JD (2009) Dyslexia: a new synergy between education and cognitive neuroscience. Science 325:280-283. CrossRef Medline

Greve DN, Fischl B (2009) Accurate and robust brain image alignment using boundary-based registration. Neuroimage 48:63-72. CrossRef Medline

Guttorm TK, Leppänen PHT, Richardson U, Lyytinen H (2001) Eventrelated potentials and consonant differentiation in newborns with familial risk for dyslexia. J Learn Disabil 34:534-544. CrossRef Medline

Guttorm TK, Leppänen PHT, Poikkeus AM, Eklund KM, Lyytinen P, Lyytinen $H$ (2005) Brain event-related potentials (ERPs) measured at birth predict later language development in children with and without familial risk for dyslexia. Cortex 41:291-303. CrossRef Medline

Hoeft F, Meyler A, Hernandez A, Juel C, Taylor-Hill H, Martindale JL, McMillon G, Kolchugina G, Black JM, Faizi A, Deutsch GK, Siok WT, Reiss AL, Whitfield-Gabrieli S, Gabrieli JD (2007) Functional and morpho- metric brain dissociation between dyslexia and reading ability. Proc Natl Acad Sci U S A 104:4234-4239. CrossRef Medline

Hoeft F, McCandliss BD, Black JM, Gantman A, Zakerani N, Hulme C, Lyytinen H, Whitfield-Gabrieli S, Glover GH, Reiss AL, Gabrieli JD (2011) Neural systems predicting long-term outcome in dyslexia. Proc Natl Acad Sci U S A 108:361-366. CrossRef Medline

Kaufman AS, Kaufman NL (2004) Kaufman Brief Intelligence Test, Ed 2. San Antonio, TX: Pearson Assessments.

Keller TA, Just MA (2009) Altering cortical connectivity: Remediationinduced changes in the white matter of poor readers. Neuron 64:624631. CrossRef Medline

Klingberg T, Hedehus M, Temple E, Salz T, Gabrieli JD, Moseley ME, Poldrack RA (2000) Microstructure of temporo-parietal white matter as a basis for reading ability: Evidence from diffusion tensor magnetic resonance imaging. Neuron 25:493-500. CrossRef Medline

Lebel C, Beaulieu C (2011) Longitudinal development of human brain wiring continues from childhood into adulthood. J Neurosci 31: 10937-10947. CrossRef Medline

Lyon GR, Shaywitz SE, Shaywitz BA (2003) A definition of dyslexia. Annals of Dyslexia 53:1-14. CrossRef

Maurer U, Bucher K, Brem S, Benz R, Kranz F, Schulz E, van der Mark S, Steinhausen HC, Brandeis D (2009) Neurophysiology in preschool improves behavioral prediction of reading ability throughout primary school. Biol Psychiatry 66:341-348. CrossRef Medline

Melby-Lervåg M, Lyster SA, Hulme C (2012) Phonological skills and their role in learning to read: a meta-analytic review. Psychol Bull 138:322-352. CrossRef Medline

Molfese DL (2000) Predicting dyslexia at 8 years of age using neonatal brain responses. Brain Lang 72:238-245. CrossRef Medline

Nagy Z, Westerberg H, Klingberg T (2004) Maturation of white matter is associated with the development of cognitive functions during childhood. J Cogn Neurosci 16:1227-1233. CrossRef Medline

Niogi SN, McCandliss BD (2006) Left lateralized white matter microstructure accounts for individual differences in reading ability and disability. Neuropsychologia 44:2178-2188. CrossRef Medline

Odegard TN, Farris EA, Ring J, McColl R, Black J (2009) Brain connectivity in non-reading impaired children and children diagnosed with developmental dyslexia. Neuropsychologia 47:1972-1977. CrossRef Medline

Paris SG (2005) Reinterpreting the development of reading skills. Reading Research Quarterly 40:184-202. CrossRef

Pennington BF (1990) The genetics of dyslexia. J Child Psychol Psychiat 31:193-201. CrossRef Medline

Pennington BF, Lefly DL (2001) Early reading development in children at family risk for dyslexia. Child Dev 72:816-833. CrossRef Medline

Qiu D, Tan LH, Zhou K, Khong PL (2008) Diffusion tensor imaging of normal white matter maturation from late childhood to young adulthood: Voxel-wise evaluation of mean diffusivity, fractional anisotropy, radial and axial diffusivities, and correlation with reading development. Neuroimage 41:223-232. CrossRef Medline

Raschle NM, Chang M, Gaab N (2011) Structural brain alterations associated with dyslexia predate reading onset. Neuroimage 57:742-749. CrossRef Medline

Raschle NM, Zuk J, Gaab N (2012) Functional characteristics of developmental dyslexia in left-hemispheric posterior brain regions predate reading onset. Proc Natl Acad Sci U S A 109:2156-2161. CrossRef Medline

Rauschecker AM, Deutsch GK, Ben-Shachar M, Schwartzman A, Perry LM, Dougherty RF (2009) Reading impairment in a patient with missing arcuate fasciculus. Neuropsychologia 47:180-194. CrossRef Medline

Rezaie R, Simos PG, Fletcher JM, Cirino PT, Vaughn S, Papanicolaou AC (2011) Temporo-parietal brain activity as a longitudinal predictor of response to educational interventions among middle school struggling readers. J Int Neuropsychol Soc 17:875-885. CrossRef Medline

Richards T, Stevenson J, Crouch J, Johnson LC, Maravilla K, Stock P, Abbot R, Berninger V (2008) Tract-based spatial statistics of diffusion tensor imaging in adults with dyslexia. Am J Neuroradiol 29:1134-1139. CrossRef Medline

Rimrodt SL, Peterson DJ, Denckla MB, Kaufmann WE, Cutting LE (2010) White matter microstructural differences linked to left perisylvian language network in children with dyslexia. Cortex 46:739-749. CrossRef Medline

Rolheiser T, Stamatakis EA, Tyler LK (2011) Dynamic processing in the 
human language system: Synergy between the arcuate fasciculus and extreme capsule. J Neurosci 31:16949-16957. CrossRef Medline

Schatschneider C, Fletcher JM, Francis DJ, Carlson CD, Foorman BR (2004) Kindergarten prediction of reading skills: a longitudinal comparative analysis. Journal of Educational Psychology 96:265. CrossRef

Shaywitz BA, Shaywitz SE, Pugh KR, Mencl WE, Fulbright RK, Skudlarski P, Constable RT, Marchione KE, Fletcher JM, Lyon GR, Gore JC (2002) Disruption of posterior brain systems for reading in children with developmental dyslexia. Biol Psychiat 52:101-110. CrossRef Medline

Silani G, Frith U, Demonet JF, Fazio F, Perani D, Price C, Frith CD, Paulesu E (2005) Brain abnormalities underlying altered activation in dyslexia: a voxel based morphometry study. Brain 128:2453-2461. CrossRef Medline

Smith SM, Nichols TE (2009) Threshold-free cluster enhancement: Addressing problems of smoothing, threshold dependence and localisation in cluster inference. Neuroimage 44:83-98. CrossRef Medline

Smith SM, Jenkinson M, Woolrich MW, Beckmann CF, Behrens TE, Johansen-Berg H, Bannister PR, De Luca M, Drobnjak I, Flitney DE, Niazy RK, Saunders J, Vickers J, Zhang Y, De Stefano N, Brady JM, Matthews PM (2004) Advances in functional and structural MR image analysis and implementation as FSL. Neuroimage 23:S208-S219. CrossRef Medline

Smith SM, Jenkinson M, Johansen-Berg H, Rueckert D, Nichols TE, Mackay CE, Watkins KE, Ciccarelli O, Cader MZ, Matthews PM, Behrens TE (2006) Tract-based spatial statistics: Voxelwise analysis of multi-subject diffusion data. Neuroimage 31:1487-1505. CrossRef Medline

Snowling M, Stothard S, Clarke P, Bowyer-Crane C, Harrington A, Truelove E, Nation K, Hulme C (2010) York Assessment of Reading for Comprehension. London: GL Education Group.

Steinbrink C, Vogt K, Kastrup A, Müller HP, Juengling FD, Kassubek J, Riecker A (2008) The contribution of white and gray matter differences to developmental dyslexia: insights from DTI and VBM at 3.0 T. Neuropsychologia 46:3170-3178. CrossRef Medline

Strickland DS (2002) The importance of effective early intervention. In: What research has to say about reading instruction, Ed 3 (Farstrup AE, Samuels SJ, eds), pp 69-86. Newark, DE: International Reading Association.

Tanaka H, Black JM, Hulme C, Stanley LM, Kesler SR, Whitfield-Gabrieli S, Reiss AL, Gabrieli JD, Hoeft F (2011) The brain basis of the phonological deficit in dyslexia is independent of IQ. Psychol Sci 22:1442-1451. CrossRef Medline

Thiebaut de Schotten M, Cohen L, Amemiya E, Braga LW, Dehaene S (2012) Learning to read improves the structure of the arcuate fasciculus. Cereb Cortex. Advance online publication. Retrieved Feb. 21, 2013. doi:10.1093/ cercor/bhs383. CrossRef Medline
Tisdall MD, Hess AT, Reuter M, Meintjes EM, Fischl B, van der Kouwe AJ (2012) Volumetric navigators for prospective motion correction and selective reacquisition in neuroanatomical MRI. Magn Reson Med 68:389-399. CrossRef Medline

Torgesen JK (2004) Preventing early reading failure-and its devastating downward spiral. American Educator 28:6-19.

Torgesen JK, Wagner RK, Rashotte CA, Rose E, Lindamood P, Conway T, Garvan C (1999) Preventing reading failure in young children with phonological processing disabilities: group and individual responses to instruction. Journal of Educational Psychology 91:579-593. CrossRef

van der Kouwe AJ, Benner T, Salat DH, Fischl B (2008) Brain morphometry with multiecho MPRAGE. Neuroimage 40:559-569. CrossRef Medline

Vandermosten M, Boets B, Wouters J, Ghesquière P (2012a) A qualitative and quantitative review of diffusion tensor imaging studies in reading and dyslexia. Neurosci Biobehav Rev 36:1532-1552. CrossRef Medline

Vandermosten M, Boets B, Poelmans H, Sunaert S, Wouters J, Ghesquière P (2012b) A tractography study in dyslexia: neuroanatomic correlates of orthographic, phonological and speech processing. Brain 135:935-948. CrossRef Medline

Wagner RK, Torgesen JK (1987) The nature of phonological processing and its causal role in the acquisition of reading skills. Psychological Bulletin 101:192-212. CrossRef

Wagner RK, Torgesen JK, Rashotte CA (1999) Comprehensive test of phonological processing. Austin, TX: Pro-Ed.

Wolf M, Denckla MB (2005) RAN/RAS: Rapid Automatized Naming and Rapid Alternating Stimulus Tests. Austin, TX: Pro-Ed.

Woodcock RW (1998) Woodcock Reading Mastery Tests-Revised/Normative Update. Circle Pines, MN: American Guidance Service.

Yamada Y, Stevens C, Dow M, Harn BA, Chard DJ, Neville HJ (2011) Emergence of the neural network for reading in five-year-old beginning readers of different levels of pre-literacy abilities: An fMRI study. Neuroimage 57:704-713. CrossRef Medline

Yeatman JD, Dougherty RF, Rykhlevskaia E, Sherbondy AJ, Deutsch GK, Wandell BA, Ben-Shachar M (2011) Anatomical properties of the arcuate fasciculus predict phonological and reading skills in children. J Cogn Neurosci 11:3304-3317. CrossRef Medline

Yeatman JD, Dougherty RF, Ben-Shachar M, Wandell BA (2012) Development of white matter and reading skills. Proc Natl Acad Sci U S A 109: E3045-E3053. CrossRef Medline

Yendiki A, Panneck P, Srinivasan P, Stevens A, Zöllei L, Augustinack J, Wang R, Salat D, Ehrlich S, Behrens T, Jbabdi S, Gollub R, Fischl B (2011) Automated probabilistic reconstruction of white-matter pathways in health and disease using an atlas of the underlying anatomy. Front Neuroinform 5:23. CrossRef Medline 